\title{
A INTERNACIONALIZAÇÃO DO DIREITO E 0 BINÔMIO “VIDA E MORTE”: REFLEXÕES À LUZ DA DIGNIDADE HUMANA E DE UMA CULTURA COSMOPOLITA
}

\author{
THE INTERNATIONALIZATION OF LAW AND THE BINOMIAL \\ "LIFE AND DEATH": REFLECTIONS IN LIGHT OF HUMAN \\ DIGNITY AND OF A COSMOPOLITAN CULTURE
}

Géssica Adriana Ehle

Valéria Ribas do Nascimento

\section{Resumo}

Ao passo da dissolução das fronteiras interestatais e da emergência de uma sociedade global, verifica-se a internacionalização do Direito, bem como a afirmação do cosmopolitismo. Por esse viés, este estudo analisa o direito à vida e a morte, contrapondo universalismos e relativismos jurídicos, a fim de determinar a viabilidade da concretude da autonomia para morrer como um direito universalizável, apropriando-se do princípio da dignidade humana como fonte de ligação entre a dicotomia mencionada. Para tanto, o método de abordagem empregado foi o dedutivo, e o de procedimento bibliográfico aliado à técnica de pesquisa por meio de resumos.

Palavras-chave: Cosmopolitismo. Dignidade humana. Vida e morte.

\begin{abstract}
Whith the dissolution of inter-State borders and the emergence of a global society, the internationalization of law, as well as the affirmation of cosmopolitanism, can be observed, with this point of view study examines the right to life and death, opposing universalisms and legal relativism, in order to determine the feasibility of concreteness of autonomy to die as a Universalizable law, taking the principle of human dignity as source of link
\end{abstract}


between the dichotomy mentioned. In order to do so, the method of approach used was the deductive as well as the bibliographical procedure, allied to the research technique of abstracts.

Key-words: Cosmopolitanism. Human dignity. Life and death.

\section{INTRODUÇÃo}

A formação da atual sociedade global e cosmopolita impõe um inovador cenário de reflexão sobre alguns institutos normativos. Muito embora tais institutos possam versar sobre direitos reconhecidos preteritamente, pode-se perceber a necessidade de uma reavaliação de tais dispositivos, ou seja, de um desvelar normativo, para que o Direito cumpra seu papel e se reformule de acordo com os fatos vivenciados ao tempo presente.

À luz de tais aspirações, uma vez demonstrado o emergir de um novo contexto social, traz-se à discussão antigos direitos para serem passíveis de nova reflexão, é o caso da autonomia para morrer, ou ainda, direito de morrer com dignidade. Nesse linear, uma vez considerada a autonomia do sujeito desvela-se, a partir do direito à vida, um direito de se caminhar para a morte de forma digna, de modo que a dignidade humana sirva como corrimão de sustentação ao indivíduo até que se achegue a terminalidade da vida.

Entrementes, muito embora se verifique tal pertinência no sobrelevar dos direitos de viver e morrer de forma digna, muito se discute quanto às acepções acerca do que cada indivíduo compreende por dignidade. De tal modo, faz-se pertinente refletir sobre a autonomia e as liberdades individuais, o poder que cada sujeito detém sobre sua própria vida e as deliberações que pode firmar ante sua morte.

Sobre tal refletir, em tempos de uma sociedade global e em face da internacionalização do Direito, atendendo às aspirações do cosmopolitismo, visa-se discutir sobre o direito de autonomia do indivíduo diante de sua própria morte. Corrobora-se, de tal forma, a premissa de que, por meio de um olhar cosmopolita, há que se almejar o resguardar de direitos, ainda que de ordem individual. Confrontam-se, a esse intento, as argumentações dos defensores do relativismo local ante o discurso 
universalista dos direitos humanos, sopesando o enquadrar do direito de morrer com dignidade.

De forma pertinente caberá, ao devido tempo, trazer à baila a discussão em face da cultura como fator limítrofe a universalização de direitos humanos, sobretudo os atinentes à vida e a morte. Estende-se um olhar panorâmico a partir dos ideais cosmopolitas às tratativas a despeito da autonomia dos indivíduos em face do direito à vida e as mortes dignas, buscando o reconhecimento de um direito comum a todos.

Por assim dizer, diante da busca pela universalização de um direito de morrer com dignidade, tem-se garantido um direito humano e, diante de tal assertiva, um direito extensivo à generalidade dos seres humanos, visando transpor quaisquer fronteiras estatais e, de modo aprioristicamente utópico, dissipar possíveis barreiras culturais. Esforços conjuntos dirigidos a resguardar a dignidade da vida humana, ainda que em tempos de terminalidade.

\section{O PROCESSO DE INTERNACIONALIZAÇÃO DO DIREITO: BREVES CONSIDERAÇÕES}

À luz de uma sociedade que delineia seus entornos em face dos efeitos da globalização e do capitalismo pós-revolucionário, vê-se estabelecido um novo parâmetro às trocas informacionais, de modo que as barreiras entre os espaços local e global foram efetivamente rompidas. De tal modo, é com um olhar transcendente que se almeja discorrer o presente estudo, em face da globalização, dos novos rumos traçados com a internacionalização do Direito, bem como quanto às premissas estabelecidas pelos defensores do cosmopolitismo, tecendo considerações acerca da universalização de direitos humanos, sobretudo quanto ao direito de morrer com dignidade.

Inerente a tal cenário de reconstrução do espaço, de transformações entre o local e o global, insurge, propulsionando tal interação, o fenômeno da globalização. Trata-se, nas palavras de Santos (2013, p. 4546), do ápice da internacionalização, a amplificação de todos os lugares e de todos os indivíduos, embora em graus diversos; uma nova fase da 
história humana, na qual a globalização constitui um paradigma para a compreensão dos diferentes aspectos da realidade contemporânea. Cita também a insurgência da instantaneidade da informação globalizada, de modo que essa acaba por aproximar lugares distantes - geográfica e socialmente - viabilizando a troca de conhecimento de modo instantâneo e simultâneo, dando origem a uma relação unitária na escala mundo.

Por assim dizer, a globalização trouxe consigo inúmeras transformações de cunho social, e não meramente econômico, de modo que Bauman (1999, p. 68) assegura que a "globalização não diz respeito ao que todos nós, ou pelo menos os mais talentosos e empreendedores, desejamos ou esperamos fazer, mas diz respeito ao que está acontecendo a todos nós". Dessa forma, a globalização abarca uma teia espessa de discussões acerca de suas beneficies e quanto aos efeitos negativos que pode acarretar.

Uma vez inseridos em um contexto global, os indivíduos se veem imersos em um ambiente cada vez mais unificado, presenciando sua cultura de espaço local ser modificada, de modo que lhes é permitido vislumbrar as consequências de todo o processo de rompimento entre as fronteiras locais até então estabelecidas. Nesse linear, fez-se notória a configuração da mundialização do espaço geográfico, sobrevindo o gênesis de um paradigma social baseado na ciência, tecnologia e informação, espaço em que as tensões entre localidade e globalidade só fazem aumentar, paralelamente ao processo de globalização (SANTOS, 2013, p. 47).

Por esse caminhar, diante do progresso da globalização, verifica-se o avançar de fluxos que se instituem de modo a transcenderem os espaços territoriais dos Estados, demonstrando a necessidade de se refundar a concepção de soberania e de territorialidade, intuindo encontrar respostas que satisfaçam as demandas nascidas desse novo paradigma de sociedade.

Por conseguinte, uma vez que a globalização afete diretamente a ideia de soberania dos Estados, enseja-se uma mudança de perfil, de forma que a soberania deixa de ser uma exteriorização do monopólio e da força política sobre um território para configurar uma soberania interdependente, oriunda da ligação entre os Estados; há o rompimento da identidade nacional no instante em que se formam blocos supranacionais, ou quando da configuração de fluxos migratórios, ou ainda, pelos conflitos de nacionalidade (MORAIS; NASCIMENTO, 2010, p. 29-31). 
Diante de tais considerações, frente ao surgimento de um modelo de sociedade global, em que se pode visualizar o nascer de um espaço mundializado, passa-se a refletir sobre a proteção concedida aos direitos humanos, sua adequação em face de tal panorama social. Ou seja, tendo em vista o reconfigurar das fronteiras interestatais, e a superação das demandas que ensejavam apenas aspirações locais, faz-se oportuno verberar acerca dos direitos humanos e de sua trajetória de internacionalização.

Em meados do século XIX, teve início a primeira fase de internacionalização dos direitos humanos, de forma a sobrelevar a busca pelo direito humanitário - voltado à proteção dos soldados das guerras -, a luta contra a escravidão e a busca pelo reconhecimento de direitos ao trabalhador assalariado. Nesse linear, com o emergir da Segunda Guerra Mundial a humanidade compreendeu, a duras penas, o salutar valor da dignidade humana, de modo que o sofrimento da guerra ensejou a afirmação à proteção dos direitos humanos (COMPARATO, 2003, p. 54-55).

Com tal trilhar, uma vez aprovada a Declaração Universal dos Direitos Humanos pela Assembleia Geral das Nações Unidas, em 10 de dezembro de 1948, desvela-se o reconhecimento de que a própria humanidade como um todo, deve estar envolta de um reconhecer de direitos. A esse despeito, "a humanidade vê-se desafiada a construir um novo paradigma jurídico-político de convivência para além das fronteiras nacionais" (SALDANHA; MORAIS; VIEIRA, 2013, p. 456).

Dessa forma, nas palavras de Comparato (2003, p. 56-57), insurge uma sólida dicotomia no que concerne ao tratamento futuro que receberão os direitos humanos, sendo a primeira hipótese a de que a humanidade cederá à força dos interesses militares e econômicos, de modo a sobrelevar uma coesão meramente técnica entre os diferentes povos e Estados ou, em contrapartida, será construída uma cidadania mundial que evidenciará o integral respeito aos direitos humanos.

Vê-se, hodiernamente, um avançar das discussões que almejam o estabelecer de uma cidadania mundial, que defendem a universalidade dos direitos humanos e da humanidade, que determinam como cerne do comprometimento da jurisdição atual, a luta pela internacionalização do Direito de modo a consolidar as premissas cosmopolitas. Tal efetivação garantiria um movimento em sentido inverso daquele que acarreta, 
diuturnamente, segregação e dissonância - fala-se da globalismo em seu aspecto puramente econômico ${ }^{1}$.

Entrementes, diante do internacionalizar do Direito e do galgar da concretização do cosmopolitismo, surgem críticas no tocante à diversidade cultural ante o alastramento dos ideais universalistas. Nesse sentido, com a internacionalização do direito tendo acarretado nítidas transformações no que tange à soberania dos Estados, visualiza-se um período em que as trocas entre os povos devem acarretar consequências positivas, quando da disseminação de direitos em escala global - direitos humanos a serem garantidos a todas as gentes.

Diante de tal desiderato, qual seja o sopesar entre os extremos do universalismo - que soterra culturas locais - ante o relativismo - que não concede espaço à universalização de direitos -, elucida-se ao próximo capítulo a insurgência da proteção aos direitos humanos, ou ainda, direitos da humanidade, substancialmente elencados por entre o rol de direitos mínimos a serem garantidos a todos os indivíduos.

\section{A PROTEÇÃO AOS DIREITOS HUMANOS E O EMBATE EN- TRE UNIVERSALISTAS E RELATIVISTAS}

Voltando-se o olhar aos tempos primórdios da origem dos direitos humanos, remonta-se ao século $\mathrm{V}$ a. $\mathrm{C}$., período em que nasce a filosofia e o indivíduo passa a pautar-se pelo saber lógico da razão. Por meio de tal trilhar, o ser humano torna-se dotado de liberdade, considerado em sua igualdade essencial, de modo que insurgem, sob tal égide, os fundamentos para a compreensão da pessoa humana como portadora de direitos inerentes a si mesmas e, sobretudo, universais os direitos humanos (COMPARATO, 2003, p. 11).

Conforme anteriormente mencionado, a proteção aos direitos humanos em escala global originou-se com a entrada em vigor da Declaração Universal dos Direitos Humanos ao ano de 1948, sendo reabastecida por novos institutos ao longo dos anos e com o emergir de novas demandas. Entrementes, cabe breve explanar no tocante à proteção regional conferida a tais direitos, especialmente para melhor versar sobre as distinções a serem enfrentadas ao tempo de se falar em uma universalização de direitos. 
O primeiro sistema a ser elucidado trata-se do Sistema Interamericano de Proteção dos Direitos Humanos, composto por diversos instrumentos normativos que trazem como elemento comum entre si a fundamental importância da proteção à dignidade da pessoa humana, sem que se faça a distinção de raça, credo, nacionalidade ou gênero (art. $3^{\circ}$. l, Carta da OEA). Como crítica a esse sistema, transparece o fato de que ainda apresenta-se pouco conhecido por entre os Estados incorporadores, sobretudo em termos de Brasil, algo a se evoluir ao passo da instituição do novo paradigma social vivenciado.

Outro sistema de proteção aos direitos humanos é o Sistema Regional Europeu de Direitos Humanos, nascido com a aprovação da Convenção Europeia de Direitos Humanos, em 1950, resguardando os direitos feridos com o recente término da Segunda Guerra. Dentre todos os sistemas regionais de proteção aos direitos humanos, o Sistema Europeu mostra-se o mais avançado, não obstante seu voluptuoso número de jurisprudências produzidas, o que mostra a preocupação em sanar as aspirações dos países integradores do Sistema (MAZZUOLI, 2011, p. 76).

A despeito da Convenção Europeia de proteção aos Direitos Humanos, Delmas-Marty (2004, p. 235 e ss.) demostra sua preocupação em zelar pelo pluralismo normativo e pelas especificidades nacionais, elegendo a Europa como uma espécie de laboratório para descrever suas previsões no sentido de promover a primazia dos direitos do homem em um sistema específico, mas que serviria como modelo a ser seguido em escala mundial.

O terceiro, e mais recente, sistema de proteção aos direitos humanos é o Sistema Regional Africano de Direitos Humanos, que nasce da aprovação da Carta Africana de Direitos Humanos e dos Povos, tendo entrado em vigor ao ano de 1986. Como sua condição peculiar, a Carta Africana trouxe em seu texto a proteção aos direitos civis e políticos, mas também aos direitos sociais, econômicos, culturais, "dos povos" - sobre esse último vê-se a proteção sobrelevar dos direitos da coletividade, o que não encontra correspondência nos Sistemas Interamericano e Europeu (MAZZUOLI, 2011, p. 80-81).

De fronte à proteção dedicada especialmente à tutela dos direitos dos povos, mostra-se evidente o abismo existente entre o vivenciar dos 
direitos no Sistema Africano, acima de tudo por reconhecerem sua rica e diversa cultura e resguardarem a importância da salvaguarde de direitos pela via da proteção coletiva. Assim sendo, aparentemente ergue-se uma barreira entre esse Sistema e os demais, especialmente no que diz respeito ao tratamento dos direitos humanos.

Considerando que o Sistema Regional Africano reverencie sua heterogeneidade e suas singularidades, tais particularismos trazem consigo uma gama de consequências que dificultam a proteção equânime aos direitos humanos de seus indivíduos. No tocante a esse tutelar, "a insuficiência e precariedade de recursos, a falta de mecanismos de proteção adequados aos habitantes da região e o baixo nível de cumprimento das decisões pelos Estados-parte" (MAZZUOLI, 2011, p.93), acabam por comprometer a atuação protetiva à efetivação dos direitos humanos por parte da Corte Africana.

Evidencia-se, por todo o exposto, a construção de um Sistema Global e de Sistemas Regionais preocupados com a tutela dos direitos humanos, visando garantir a todos os indivíduos um corpo de direitos mínimos necessários a mantença da condição de dignidade - direito que lhes é atribuído como inerente a sua condição de pessoa. Contudo, fazem-se notórias as disparidades enfrentadas em face de cada um dos Sistemas, de modo que o avançar global mostra-se desafiador, ainda quando se fala em garantir a dignidade.

Ao vivenciar de tempos em que o Direito internacionaliza-se, não deve se desmerecer a identidade cultural de cada povo, pois é fator crucial para assegurar a diversidade das sociedades, tão rica e de tão grande valia. No entanto,

a questão que se põe e que se impõe é mesmo a de encontrar as vias e os meios par dar conta, de uma parte, da universalidade jurídica provocada pela internacionalização do direito e, de outra parte, do relativismo que se rebela contra o império da globalização econômica (SALDANHA, 2016, p. 151).

Desse modo, pode-se vislumbrar uma dicotomia sólida a insurgir ante a defesa da universalidade dos direitos humanos, quando da severa crítica de um soterramento de culturas locais, um avançar de garantismos que não se presta a salvaguarda das diversidades e características únicas 
regionais. Ademais, corroboram tal posicionar, os argumentos de que a universalização promoveria o domínio dos Estados reconhecidos como potências mundiais sobre aqueles já anteriormente colonizados, seria um novo processo de colonialismo aos tempos contemporâneos.

De tal modo, uma vez que se pretenda a universalização de um conjunto de direitos mínimos, está-se falando na construção de uma comunidade mundial de valores, sendo inegável "o risco da hegemonia dos Estados mais fortes sobre os mais fracos, como também o do esfacelamento da diversidade cultural e das tradições" (SALDANHA; MORAIS; VIEIRA, 2013, p. 458). Contudo, tal defender mostra-se transponível, sobretudo ao momento em que busca nos ditames do cosmopolitismo a satisfação para as incongruências oriundas de tal embate.

A busca por um pensamento de garantia de direitos mínimos, de um direito comum a todos os indivíduos não é algo novo originário da sociedade global, mas merece um novo desvelar aos tempos presentes. Prova disso é sua defesa já nas verberações de Kant (2008, p. 22), quando elucida que "a ideia de um direito cosmopolita não é nenhuma representação fantástica e extravagante do direito, mas um complemento necessário de código não escrito, tanto do direito político como do direito das gentes", talhando seu desejo pelo desenvolvimento de uma federação livre de Estados.

Por meio de tais premissas é possível assentar a busca por um universalismo que não afronta direitos, não busca impor culturas e pensamentos hegemônicos, destoa de aspirações que almejem extirpar a diversidade nacional dos Estados - um universalismo cosmopolita.

À luz do que defende o cosmopolitismo, traça-se uma rota para a universalização de um direito comum para toda a humanidade, sem deixar de observar os particularismos existentes, é um caminho de sentido oposto ao vivenciado em tempos de colonização, é a busca pela garantia de direitos humanos em face da promoção da dignidade, entendida como direito basilar e fundante de todos os demais - inclusive sobre os que versem sobre questões culturais.

Um olhar cosmopolita intenciona, diante da internacionalização do direito, em face da insurgência de inúmeras crises que abarcam a sociedade de forma global e, ainda, ante a superação da rígida ideia de soberania na- 
cional e civilização como um binômio indissolúvel, "perdem a obrigatoriedade as velhas diferenciações entre dentro e fora, nacional e internacional, nós e eles, sendo preciso um novo realismo, de caráter cosmopolita para que se possa sobreviver" (BECK, 2004, p. 25, tradução nossa).

Vê-se, por meio de tal enfrentar, a solidez dos ideais de superação com relação às fronteiras impostas pelos canteiros entre os Estados, de modo que a porosidade faz-se presente, contribuindo para com o alastrar do comprometimento em relação à busca por um direito comum. Ainda assim, persistem as argumentações quanto à universalidade ser algo negativo para a soberania nacional dos Estados, posição especialmente defendida pelos expoentes do capitalismo, interessados no disseminar do globalismo.

Nesse ínterim, uma vez que se defenda que os direitos humanos promovam valores universais, aplicáveis intrinsicamente a todos, surgem inúmeras dúvidas quanto ao já referido soterrar de culturas. Contudo, de acordo com o delinear das acepções cosmopolitas, vê-se o transcender das pretensões individuais dos Estados, estendendo-se a todos os membros da comunidade universal, de modo que todos se comprometam com o reconhecimento e o respeito para com os direitos legítimos dos demais países (HELD, 1997, p. 272-273).

Muito embora se traga à lume a fundamentalidade de se resguardar os direitos referentes à cultura de cada Estado, no sentido de respeitar suas tradições e valores, verbera-se sobre o quanto se faz imprescindível o tutelar dos direitos humanos em escala global, a busca por um direito comum. Notoriamente, diante de tal busca por uma universalização do comum, insurgem-se argumentações afirmando que alguns direitos seriam de responsabilidade dos Estados, ou seja, a proteção jurídica desses institutos restaria melhor atingida ao passo que se permitisse o deliberar interno das nações.

Ao que versa o presente estudo, intui-se a análise do direito à vida e sua extensão a um possível direito de morrer, sobrelevando a dignidade humana como argumento para sua universalização. Dito de outro modo, enfrenta-se ao próximo tópico o diálogo entre o binômio vida e morte, trazendo à luz uma cultura cosmopolita de assimilação do outro e, sobretudo velando a busca por um direito comum. 


\section{BINÔMIO VIDA E MORTE: A DIGNIDADE HUMANA E A (IN)VIABILIDADE DA UNIVERSALIZAÇÃO DO DIREITO DE MORRER}

Ao contemplar de todo o caminhar, pode-se compreender a fundamentalidade da dignidade humana, seja em escala global de proteção haja vista a Declaração Universal dos Direitos Humanos - ou diante do observar de cada um dos Sistemas Regionais de proteção aos direitos humanos. Tudo isso porque a dignidade humana encontra-se incorporada e diretamente ligada à proteção dos direitos humanos, sendo parte de suas fundações.

Não bastasse tal proteção, cabe breves verberas acerca do tratamento conferido à dignidade humana em âmbito de direito interno. Sendo assim, com o advento da Constituição Federal de 1988, a República Federativa do Brasil passou a constituir-se sob um regime de Estado Democrático de Direito, que estabelece desde seu art. 1ํㅡㄴ, III, a Dignidade da Pessoa Humana como um de seus fundamentos (BRASIL, 1988). Projeta-se, diante de tal taxativa proteção, o comprometimento para com a observância da dignidade humana no exercício da proteção de direitos, desde direitos tidos como individuais, até mesmo com relação aos direitos humanos.

Neste mesmo sentido, esclarece Reale (1963, p. 25) que por se tratar de um fundamento do Estado Democrático de Direito, aloca-se como esteio de sustentação a todo ordenamento jurídico nacional, defendendo que a dignidade da pessoa acaba por constituir-se como um fundamento da sociedade e do estado, devendo ser atemporal com relação a quaisquer avanços no tocante as mutações sociais diuturnamente vivenciadas.

Ademais, à dignidade humana é difícil que se atribua um conceito fechado, rígido e absoluto, contudo, Sarlet (2006, p. 236-237) define-a como:

a qualidade intrínseca e distintiva reconhecida em cada ser humano que o faz merecedor do mesmo respeito e consideração por parte do Estado e da comunidade, implicando, neste sentido, um complexo de direitos e deveres fundamentais que assegurem a pessoa tanto contra todo e qualquer ato de cunho degradante e desumano, como venham a lhe garantir as condições 
existenciais mínimas para uma vida saudável, além de propiciar e promover sua participação ativa e corresponsável nos destinos da própria existência e da vida em comunhão com os demais seres humanos.

Dessa forma, com o exposto é possível notar a presença da dignidade humana na correlação interpessoal em sociedade e ainda a ideia de que todo ser humano deve ser tratado dentro de um mesmo contexto de respeito a sua condição humana, de forma que "o caráter único e insubstituível de cada ser humano, portador de um valor próprio, veio demonstrar que a dignidade da pessoa existe singularmente em todo o indivíduo" (COMPARATO, 2003, p.31).

Seguindo por tal caminhar, torna-se possível verificar a preocupação em proteger o direito à vida, à luz da salvaguarda do princípio da dignidade humana. Em que pese à ligação entre dignidade humana e direito à vida e à morte, as palavras de Freitas e Zilio (2016) corroboram tal coadunar quando defendem que "a expressão 'morte digna' significa que a morte constitui uma fração da vida, por isso o modo como se dá a morte é tão importante. Morrer dignamente, assim, faz parte do processo de viver dignamente".

Hodiernamente enfrenta-se um período de crise no que diz respeito a universal proteção aos direitos humanos, sobretudo ao se evidenciarem as, já mencionadas, desigualdades entre os Estados que aspiram por um solucionar com base na compreensão de um constitucionalismo mundial que forneça as coordenadas para uma democracia que ultrapasse as fronteiras dos países (FERRAJOLI, 2007, p. 88-89). Daí a importância de um olhar através do avançar da internacionalização do Direito com base no cosmopolitismo.

Entrementes, para que o direito à vida passe a integrar o Direito Comum, é preciso que se corrobore sua relação direta com a defesa da dignidade como sendo elemento intrínseco à humanidade inteira, de modo que comporia - ainda no plano da projeção - o que Delmas-Marty (2004, p. 298-299) chama de irredutível humano, um conjunto de direitos inderrogáveis que dizem respeito ao indivíduo e a coletividade. Nesse sentido, tais direitos seriam asseguráveis a todos os seres humanos, ou seja, originariam uma tutela universal de proteção. 
Ainda de acordo com Delmas-Marty (2008, p. 06), existem inúmeras peculiaridades culturais locais que geram um enorme abismo para a efetiva garantia de um irredutível humano e, no que se refere às concepções acerca da vida e da morte, citando o instituto da eutanásia ${ }^{2}$, afirma que deve ser matéria de apreciação e deliberação por parte dos Estados. Reitera ainda a autora, que respostas universalizáveis seriam possíveis, do ponto de vista da criação de uma comunidade mundial de valores, quando se trata da vida e da morte, deve-se pensar sobre a proibição da clonagem humana e a abolição da pena de morte.

Ademais, ainda quanto à possível afirmação de um irredutível humano, para questões que envolvam moral, religião, e demais direitos que versem sobre particularismos locais, deve-se, por vezes, abrir mão de certos universalismos, de modo a promover não a unificação dos Sistemas, mas certa aproximação entre eles, por meio do respeito a um conjunto de princípios comuns (DELMAS-MARTY, 2004, p. 306). Refutando, ou não, a possibilidade de universalização de certos direitos, o que se pode observar é que muitos pontos referentes ao entroncamento dos direitos à vida e à morte com dignidade restam intocados e carecedores de reflexão.

Ao se intuir a universalização dos direitos humanos lato sensu, protege-se fundamentalmente a dignidade humana o que, por conseguinte, gera a proteção à autonomia do sujeito em decidir os rumos de sua vida. A esse despeito, reitera-se que:

a nova universalidade procura, enfim, subjetivar de forma concreta e positiva os direitos da tríplice geração na titularidade de um indivíduo, que antes de ser homem deste, ou daquele país, de uma sociedade desenvolvida, ou subdesenvolvida, é pela sua condição de pessoa um ente qualificado por sua pertinência ao gênero, objeto daquela universalidade (BONAVIDES, 2007, p. 574).

Nesse sentido, uma vez considerada a universalidade para além das fronteiras dos Estados, há algo maior a ser dividido, ideais de mundo a serem compartilhados, a dignidade humana e o respeito à vida a serem fomentados. É por esse entender que Dworkin (2009, p. 340) afirma que a vida humana tem importância intrínseca e pessoal para cada indivíduo, e que é sagrada - independentemente de acepções religiosas - a partir 
do instante em que se vivencia sua santidade, cabendo a cada pessoa humana, por meio de sua liberdade, exercer o domínio sobre ela.

A vida humana, conforme anteriormente aduzido, vem concebida como um direito fundamental e inviolável, pertencente a todas as pessoas. Contudo, a terminalidade da vida, com a iminência da morte, não pode ser compreendida como um dever de dor e sofrimento, mas sim como o fim de algo - quiçá uma passagem - podendo ser oponível erga omnes apenas se for possível que se viva bem, restando preservada a dignidade humana (SÁ; MOUREIRA, 2015, p. 96).

Todo o percorrer do presente estudo justifica-se no instante em que a solução para tal embate entre a universalização, ou não, das questões que versam sobre o fim da vida encontra-se na compreensão cosmopolita do tema. Assim sendo, "o direito de uma pessoa ser tratada com dignidade é o direito de que os outros reconheçam seus verdadeiros interesses" (DWORKIN, 2009, p.337), verificando-se a relação entre a dignidade humana inerente a cada indivíduo, mas ainda destarte o seu relacionar com o outro.

Consoante a tal explanar, refuta-se a ideia de um conceito genérico do que seria uma boa vida, como sendo algo comum a todas as pessoas. É imperioso versar sobre questões que envolvam a cultura dos povos, suas particularidades históricas que consagram o que compreendem acerca da vida e da morte humanas. Entrementes, a partir da proteção aos direitos humanos, tem-se um caminho de acesso para a universalização de um conjunto de direitos oriundos da comunidade mundial de valores, uma vez que seja sobrelevada a dignidade da pessoa humana para a integralidade da vida - sobretudo ante o achegar da morte.

Nesse linear, ao momento em que se referencia uma democracia que ultrapasse os limites interestatais, vê-se o fortalecimento das aspirações cosmopolitas, por meio do refutar dos argumentos que atribuem ao universalismo o descaso à cultura de cada país. Bastaria, segundo Pisarello (2007, p. 173, tradução nossa), que houvesse “a articulação de um modelo de direitos humanos capaz de combinar aspirações universalistas com práticas multiculturais".

Ainda que as concepções culturais de cada Estado apresentem divergências para com o correto vivenciar da terminalidade da vida, com base 
em tais prerrogativas de direitos vislumbra-se a salvaguarda da autonomia em face do caminhar para a morte, sobretudo por meio da mantença da dignidade humana. Dessa forma, universalizar os direitos humanos em face da primazia da dignidade humana, intui respeitar a liberdade individual, sobretudo incentivando a liberdade de se deliberar sobre a própria morte, um governo que nega tal direito é totalitário e não atinge as premissas de um Estado Democrático (DWORKIN, 2009, p. 342-343).

Observa-se que as vicissitudes particulares referentes à cultura regionalista dos povos não resta prejudicada ao passo que se respeite sua dignidade humana, fundamento para a construção de um irredutível humano. Dessa forma, quando se apropria do argumento de que os direitos referentes à vida humana não são passíveis de universalização, nega-se o poder do cosmopolitismo em avançar na salvaguarda de direitos mínimos comuns. Nenhuma cultura local, particularidade moral ou religiosa, deve atentar contra a dignidade de se viver e morrer dignamente, o desafio lançado, portanto, reside em se repensar sobre os possíveis mecanismos de aproximação, integração, ou universalização de tais direitos.

\section{CONCLUSÃO}

Considerando o que já foi mencionado no decorrer do texto, salienta-se a importância de se estudar e enfrentar o processo de internacionalização do Direito e, para o recorte do presente trabalho, verificar novas formas de se garantir e salvaguardar os direitos humanos. Diante de tal cenário, preteriu-se a análise do cosmopolitismo como base de ensejo à defesa da universalidade do direito de morrer à luz do princípio da dignidade humana.

Nesse sentido, buscou-se demonstrar que ocorreu alteração no tocante ao sentido da soberania estatal, marcada pela superação dos ideais de nacionalismo e civilidade como elementos de ligação entre o indivíduo e o território. Conjuntamente, verberou-se sobre as prerrogativas do direito internacional, de forma a determina-lo como insustentável parâmetro para as relações originárias da nova sociedade global emergente.

Em momento seguinte, trouxe à luz as premissas de proteção aos direitos humanos, desde o surgimento das aspirações de tutela. Dessa 
forma, delineou-se o resguardar de tais direitos sobre a égide de global, ao passo da entrada em vigor da Declaração Universal dos Direitos Humanos, bem como os sistemas de proteção regionais - Interamericano, Europeu e Africano - apontando algumas de suas vicissitudes e os elementos que os fazem destoar no que se refere a proteção dos direitos humanos.

Diante do corroborar da proteção aos direitos humanos, fez-se confrontar as vertentes universalistas às relativistas, tecendo um recorte no que concerne aos direitos humanos. No intuito de promover a universalização, verberou-se quanto a despretensão de se promover um novo colonialismo diante do sobrevir da hegemonia dos Estados mais fortes por sobre os demais, ratificando postura plenamente inversa ao defender-se a afirmação dos ideais cosmopolitas.

Apropriando-se do cosmopolitismo, de suas premissas de identificação para com o outro, defendeu-se a universalidade do direito de morrer à luz da dignidade humana. Muito embora argumentações contrárias tenham sido apresentadas, demonstrando que alguns direitos merecem ser tutelados internamente pelos Estados, quando da objetivação de um direito de morrer, faz-se sobre a gôndola da dignidade humana, de um desvelar do direito à vida e, desse modo, um direito a se enfrentar sua terminalidade de forma digna.

Diante de todo o exposto, há que se enfrentar a internacionalização do direito, a superveniências de direitos humanos em esfera global e a emergência de um espaço público transnacional de acordo com o cosmopolitismo jurídico. É sob tal lume que se trilha o caminho pelo qual o direito de morrer à luz da dignidade humana integrará, efetivamente, o corpo dos direitos fundamentais e, por conseguinte, o conjunto dos direitos humanos passíveis de universalização. É tempo de se apropriar da internacionalização do Direito e da reafirmação do cosmopolitismo como ferramentas de aporte para a construção de soluções às novas demandas insurgentes na sociedade global.

\section{NOTAS}

1 No que tange à globalização, faz-se oportuna breve conceituação e distinção com relação à termos similares. De modo que por globalização, compreende-se “o próprio conjunto de processos, em cujo andamento os Estados nacionais se encontram", [...] ao passo que "globalismo significa a 
concepção de que o mercado substitui ou acaba com a própria ação política, incorporando a ideologia do neoliberalismo, restringindo-se ao aspecto econômico" [...] e ainda, "a globalidade pode ser entendida como um complexo de fatores que enlaça a economia, a cultura, a política e tudo aquilo que estiver relacionado com essas áreas" (NASCIMENTO, 2011, p. 112-113).

20 conceito de eutanásia, de acordo com Santoro (2010, pp. 117-118), pode ser descrito como "o ato de privar a vida de outra pessoa acometida por uma afecção incurável, por piedade e em seu interesse, para acabar com seu sofrimento e dor". Ainda nas palavras do autor, tal prática pode ser ainda dividida de acordo com a natureza de sua ação, tratando-se de eutanásia ativa aquela em que, por meio de uma ação direta do médico ou de interposta pessoa, consolida-se o ato de ministrar doses letais de drogas ao paciente, enquanto que a eutanásia passiva é uma conduta omissiva, em que há supressão ou interrupção nos cuidados médicos que oferecem um suporte indispensável à manutenção da vida.

\section{REFERÊNCIAS}

BAUMAN, Zygmunt. Globalização: as consequências humanas. Rio de Janeiro: Jorge Zahar Ed., 1999.

BECK, Ulrich. La mirada cosmopolita o la guerra es la paz. Barcelona: Paidós, 2004.

BONAVIDES, Paulo. Curso de direito constitucional. São Paulo: Malheiros, 1999.

BRASIL. Constituição da Republica Federativa do Brasil. 33. ed. São Paulo: Saraiva, 2004.

COMPARATO, Fábio Konder. A afirmação histórica dos direitos humanos. São Paulo: Saraiva, 2003.

DELMAS-MARTY, Mireille. Por um direito comum. São Paulo: Martins Fontes, 2004.

. Aula ministrada por Delmas-Marty. Collège de France: 18 mar. 2008. Disponível em: <https://docs.google.com/viewer?a=v\&pid=forums\&srcid=MDE00TgzMDgxOTE5MjM5MzkzNTEBMTA20TM5MjkzODQ0NTUwNDA2NDYBb m03YTN4LUdKdHdKATAuMQEBdjI>. Acesso em: 15 jun. 2016.

DWORKIN, Ronald. Domínio da vida: Aborto, eutanásia e liberdades individuais. São Paulo: WMF Martins Fontes, 2009.

FERRAJOLI, Luigi. Sobre los derechos fundamentales. In: CARBONELL, Miguel (Org.). Teoría del neoconstitucionalismo. Madrid: Trotta, p. 71-89, 2007. 
FREITAS, Riva Sobrado; ZILIO, Daniela. Os direitos da personalidade na busca pela dignidade de viver e de morrer: o direito à morte (digna) como corolário do direito à vida (digna). Revista de Direitos e Garantias Fundamentais. Vitória, v. 17, n. 1, p. 171-190, jan./jun. 2016. Disponível em: <http://sisbib.fdv.br/index. $\mathrm{php} /$ direitosegarantias/issue/view/

26/showToc>. Acesso em: 30 mar. 2017.

HELD, David. La democracia y el orden global: Del Estado moderno al gobierno cosmopolita. Barcelona, Paidós, 1997.

KANT, Immanuel. A paz perpétua: um projecto filosófico. Covilha: LusoSofia, 2008.

MAZZUOLI, Valerio de Oliveira. Os Sistemas Regionais de Proteção aos Direitos Humanos: Uma análise comparativa dos sistemas interamericano, europeu e africano. São Paulo: Revista dos Tribunais, 2011.

MORAIS, José Bolzan de; NASCIMENTO, Valéria Ribas do. Constitucionalismo e cidadania: por uma justiça constitucional democrática. Porto Alegre: Livraria do Advogado, 2010.

NASCIMENTO, Valéria Ribas do. o tempo das reconfigurações do constitucionalismo: os desafios para uma cultura cosmopolita. São Paulo: Ltr, 2011.

PISARELLO, Gerardo. Globalización, constitucionalismo y derechos: las vías del cosmopolitismo jurídico. In: CARBONELL, Miguel (Org.). Teoría del neoconstitucionalismo. Madrid: Trotta, p. 159-184, 2007.

REALE, Miguel. Pluralismo e liberdade. São Paulo: Saraiva, 1963.

SÁ, Maria de Fátima Freire de. MOUREIRA, Diogo Luna. Autonomia para morrer: Eutanásia, suicídio assistido, diretivas antecipadas de vontade e cuidados paliativos. Belo Horizonte: Del Rey, 2015.

SALDANHA, Jânia Maria Lopes. Aplicação da margem nacional de apreciação pelas cortes de direitos humanos: desafio à internacionalização do direito. In: REDIN, Giuliana; SALDANHA, Jânia Maria Lopes; SILVA, Maria Beatriz Oliveira da. Direitos emergentes na sociedade global: Programa de pós-graduação em Direito da UFSM, Editora UFSM, p. 147-171, 2016. 
SALDANHA, Jânia Maria Lopes; MORAIS, José Luis Bolzan de; VIEIRA, Gustavo Oliveira. Internacionalização do direito e bens públicos mundiais. Estudos Jurídicos, São Paulo, vol. 18, p. 454-473, 2013. Disponível em: <www.univali.br/ periodicos>. Acesso em: 20 jul. 2016.

SANTORO, Luciano de Freitas. Morte digna: 0 direito do paciente terminal. Curitiba: Juruá, 2010.

SANTOS, Milton. Técnica, Espaço e Tempo: Globalização e Meio Técnicocientífico-informacional. São Paulo: Ed. da USP, 2013.

SARLET, Ingo Wolfgang. Dignidade da Pessoa Humana e Direitos Fundamentais na Constituição Federal de 1988. Porto Alegre: Livraria do Advogado, 2006.

UNESCO. Resolução 217 A (III), de 10 de dezembro de 1948. Declaração Universal dos Direitos Humanos. Assembleia Geral das Nações Unidas. Disponível em: <http://unesdoc.unesco.org/images/0013/001394/139423por.pdf>. Acesso em: 20 jun. 2016.

Recebido em: 18-5-2017

Aprovado em: 24-1-2018

\section{Géssica Adriana Ehle}

Mestranda em Direito pela Universidade Federal de Santa Maria (UFSM); especialista em Direito Constitucional e cursando pós-graduação lato sensu em Direito do Consumidor pela Instituição de Ensino Complexo Educacional Damásio de Jesus; pesquisadora do Centro de Estudos e Pesquisas em Direito e Internet (CEPEDI). Advogada. E-mail: gessica.ehle@gmail.com

Universidade Federal de Santa Maria, Curso de Direito.

Rua Floriano Peixoto, Centro, 97015-372 - Santa Maria, RS - Brasil.

\section{Valéria Ribas do Nascimento}

Pós-doutorado em andamento na Pontifícia Universidade Católica do Rio Grande do Sul (PUC-RS); doutora em Direito Público pela Universidade do Vale do Rio dos Sinos (UNISINOS), com período de pesquisa na "Universidad de Sevilla" (US); mestre em Direito Público pela Universidade de Santa 
Cruz do Sul (UNISC); graduada em Direito pela Universidade Federal de Santa Maria (UFSM); professora do Programa de Pós-Graduação em Direito da UFSM; professora adjunta do Departamento de Direito da UFSM; coordenadora do Núcleo do Direito Constitucional (NDC) da UFSM. Email: valribas@terra.com.br

Universidade Federal de Santa Maria, Curso de Direito.

Rua Floriano Peixoto, Centro, 97015-372 - Santa Maria, RS - Brasil. 